\title{
Construction on Mobile Learning Resources
}

\author{
Li Ma ${ }^{a}$, Jun Yang \\ School of Education and Sports, Bohai University, Jinzhou, 121013, China \\ aml_mary@126.com, b444530141@qq.com
}

Keywords: mobile learning resources; construction; theories; principles; process; strategies

\begin{abstract}
Mobile learning resources are the core of mobile learning and an important guarantee for mobile learning. The development of communication technology and the popularization of mobile devices have made the construction of mobile learning resources as an important task in the construction of school resources. Guided by the basic theory, this paper follows the principles of mobile learning resource construction, designs the construction process of mobile learning resources, and proposes the mobile learning resource construction strategy. The specific process includes: pre-analysis, resource design, resource development, resource testing and resource evaluation. Specific strategy includes: setting construction goals and assessment criteria, focusing on the social attributes of mobile learning resources, mining and integrating the teaching resources of enterprises, promoting the sharing and classification of resources, and focusing on guiding learners' learning concepts.
\end{abstract}

\section{Introduction}

With the continuous integration of mobile communication technology and computer technology, as well as the increasing popularity of mobile communication terminals and wireless networks, mobile learning has received more and more attention in the field of education around the world, and has become one of the hotspots of modern educational technology research. Mobile learning is another new way of learning after digital learning. Mobile learning uses mobile communication devices to learn at any time and any place. Mobile communication devices used in mobile learning must be able to effectively present learning content and provide two-way communication between teachers and learners. Mobile learning is considered to be a future learning model, or a model that is indispensable for future learning. Mobile learning is a new type of distance education that is close to the essence of learning. It truly realizes the learning ideal of "anyone, anywhere, anytime, and learning any content", and it is a form of learning that builds the lifelong education system and creates the learning society.

With the rapid spread of mobile devices and the gradual expansion of wireless network coverage, mobile learning has become a hot learning method. Mobile learning has brought new opportunities for the development of modern education. More and more students choose to use piecemeal time to pass mobile devices. To acquire learning resources, the construction of mobile learning resources has become an important basis for mobile learning. Mobile learning resources refer to various materials that support and promote mobile learning through mobile terminal devices, including audio, video, network courseware and media materials, and are the sum of learning materials that diversify digital knowledge and information. Mobile learning resources are the core of mobile learning, and are an important source for learners to obtain mobile learning materials. They are also an important guarantee for mobile learning. Studying the construction of mobile learning resources has important theoretical and practical significance for exerting the advantages of mobile learning, improving the effect of shifting learning, and finally promoting the development of mobile learning.

\section{Construction Theories on Mobile Learning Resources}

The construction of mobile learning resources is based on the following five theories:

(1) Constructivism learning theory. This theory emphasizes the important role of meaning 
construction in the formation of knowledge, and constructs meaning as the core of learning activities. It proposes that all learning activities and ultimate goals are to complete the meaning construction of the knowledge learned. Constructivist learning theory points out that "situation", "collaboration", "conversation" and "meaning construction" are the four elements in the learning environment. Emphasize that teaching is not the transfer of knowledge, but the processing and transformation of knowledge.

(2) Situational cognitive theory. Situational learning is not only a suggestion to make the context of teaching, but a theory about the nature of human knowledge, studying how human knowledge develops in the course of activities. Teaching resources should provide real or realistic situations to reflect the application of knowledge in real life, create opportunities for understanding and experience interaction; attach importance to tacit knowledge learning, construct learning models for students, build anchored learning brackets, and train students self-confidence.

(3) Experiential learning theory. Experiential learning is an experiential activity through various real-life scenarios, enabling learners to gain emotional feelings in their own learning and inquiry activities, conceptualizing them into their own experiences, and applying them to new practices, thus affecting learners. Behavior, emotions, attitudes and values. Empirical learning theory emphasizes the importance of abstract thinking, practical activities, forming experience and reflecting observation.

(4) Informal learning theory. Informal learning refers to what happens in informal learning situations such as work, life, and social interaction. Knowledge is transmitted through non-teaching social interactions, which are initiated, self-regulated, and self-responsible by learners. Informal learning is a learning behavior spontaneously produced by learners. Individuals regulate and control the learning process. The learning initiative is in the hands of the learners. It can fully exert the individual's subjective initiative and choose to have a purposeful learning.

(5) Empirical learning theory. Experience learning refers to the process in which learners gain experience by experiencing various situations and integrate them into their own experiences to generalize and then apply them to practice to gain new experiences. The key to the acquisition of new experiences is not only to devote all of their energies to activities, to gather information to gain specific experience, but more importantly to evaluate, reflect and reapply specific experiences. It is necessary to give full play to the positive role of social factors and environmental factors in gaining experience.

\section{Construction Principles on Mobile Learning Resources}

The following principles should be followed in the construction of mobile learning resources:

(1) Standardization principle. Standardization refers to the process of establishing standard. Standard is a normative document that is used to achieve optimal order within a certain range, developed by consensus, and approved by recognized institutions for joint use or reuse. The construction of mobile learning resources should not only consider the usability at the current stage, but also consider sharing and scalability. Therefore, it is necessary to build standardized learning resources. Standardized resources can be shared on a larger scale, and the efficiency of resources used by learners or educators can be improved, while supporting data sharing and interoperability between different resource pools.

(2) Simplicity principle. Mobile communication devices have limited data processing and storage capabilities, small screens, limited resource visibility, and unlimited network speed response to resource operations. The learner's learning time is scattered and subject to high levels of interference. All of these require mobile learning resources to adhere to the principle of simplicity, simple interface, simple operation, simple text description and illustration, and are presented in an intuitive and eye-catching manner, which is easy for learners to operate. It is convenient for learners to interact and reduce input. It is basically the simple search and browse function, which reflects the convenience of mobile learning.

(3) Timeliness principle. The rapid development of science and technology, the speed of knowledge update has accelerated, and the frequency of elimination of old knowledge has been 
accelerated. Learners need to obtain the latest resources to meet the needs of learning and work. From the perspective of resource construction, rebuilding the resource cycle is long, and it requires a lot of manpower, material resources and financial resources, and it cannot meet the learners' needs for real-time learning of new knowledge. Therefore, the construction of mobile learning resources should be able to modify and support updates to reduce construction costs and improve the timeliness of learning resources. At the same time, the reasonable tracking mechanism is designed to help learners find the interrupted learning content.

(4) Miniaturization principle. The lack of relatively complete learning time for learners is a feature of mobile learning. In order to support learning in a piecemeal time period, comprehensive considerations are made from the learner's attention duration, acceptable information volume and learning environment. According to the micro-learning theory, Design a small learning module with self-contained and relative independence by using a knowledge point, a teaching link or a class of teaching activities. Each learning module has better encapsulation and relative integrity, and strives to have a moderate level of knowledge, outstanding learning points, clear difficulties, and refined content.

\section{Construction Process on Mobile Learning Resources}

The process of building mobile learning resources can be roughly divided into five steps, as shown in Fig.1.

\begin{tabular}{|c|c|c|c|c|c|c|c|c|}
\hline $\begin{array}{l}\text { Pre-phase } \\
\text { analyses }\end{array}$ & $\square$ & $\begin{array}{c}\text { Resources } \\
\text { design }\end{array}$ & 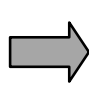 & $\begin{array}{c}\text { Resources } \\
\text { development }\end{array}$ & $\square$ & $\begin{array}{l}\text { Resources } \\
\text { testing }\end{array}$ & 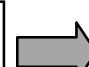 & $\begin{array}{l}\text { Resources } \\
\text { evaluation }\end{array}$ \\
\hline
\end{tabular}

Fig. 1. Construction process on mobile learning resources

(1) Pre-phase analysis. Pre-phase analysis is an important guarantee for correctly grasping the direction of mobile learning resources construction. According to the theory of teaching theory, the preliminary analysis mainly completes four aspects of work: first, learning demand analysis, understanding the gap between the current situation and expectations of learners, making resource construction more targeted; second, learner analysis, mainly the learner's learning attitude, learning motivation and learning style are analyzed; third, the learning objective analysis, according to the characteristics of mobile learning, the learning objectives should be combined with the demand for resources, and pay attention to practicality and practicality; fourth, the analysis of learning content focuses on the size of the knowledge module and the relationship between the modules, which helps to improve the educational design and develop reasonable teaching strategies.

(2) Resource design. Design mainly in two aspects: first, frame structure design, frame design is the overall idea of mobile learning resource design, system, rationality and continuity guarantee, which determines the learning content is established the way in which the context is applied. Interface design, content design, media design, usability design, interaction design, and event design for mobile learning resources need to be considered. Second, the interface design is presented. The human-machine interface is the main channel for information interaction between learners and learning resources, and has an important impact on learning effects. The human-machine interface of mobile learning resources must follow the interface design principles in the field of human-computer interaction, meet the needs of multimedia learning and cognition, and also conform to the technical characteristics of mobile devices.

(3) Resources development. Resource development is mainly in two aspects: first, material preparation, materials for mobile learning resource development, including text, pictures, audio, video and animation. Material selection should meet the learning content requirements and the principles of media selection. The material that has been digitized can be used directly after processing and finishing; some materials need to be digitized and can be used after meeting the requirements. Second, resource production, according to the requirements of preliminary analysis and resource design, use relevant materials to develop different media resources, and use the most suitable production tools according to the different characteristics of resources and the 
characteristics of tools. When integrating resources, you should consider how you can make the connection between resources more reasonable.

(4) Resources testing. Resource testing is the process of using resources to discover errors. Testing is not only an important task in the resource development phase, but also plays a very important role in the entire resource construction process. Resource testing is a key link in resource quality assurance and directly affects the quality assessment of resources. Testing should not only pay attention to strategy, but also pay attention to timeliness. After the resource development is completed, the resources need to be tested, and the resources should be revised and improved according to the problems in the test before they can be released for use by learners. In order to improve the test results, you can perform a preview test, test it in a physical device if necessary, and improve and optimize it based on actual test results.

(5) Resources evaluation. Resource evaluation refers to the process of collecting information on the use of resources, and making scientific judgments and objective measures for the process, method and effect of resource presentation according to certain objective criteria. First, whether the content evaluation meets the requirements of the learning objectives, whether it is relatively independent and complete, whether it is simple and focused; second, the performance form evaluation, whether the learning content is effectively presented in the mobile physical terminal, whether the interface design is simple and beautiful, navigation design whether the level is clear; third, the evaluation of learning effects, whether each learner can easily and quickly acquire learning resources, whether he can carry out learning anytime and anywhere, and whether the improvement obtained by learning is consistent with the expected goal.

\section{Construction Strategies on Mobile Learning Resources}

In the era of mobile Internet, the mobile learning model frees learners from the limitations of time, place and space. The construction of mobile learning resources plays an important role in the implementation and promotion of this new learning model. Following the principles of mobile learning resource construction, the strategies proposed in this paper are as follows:

(1) Formulate construction goals and assessment criteria. The construction of mobile learning resources requires a good top-level design, a long-term goal and a phase goal of planning and construction. The goal is to be realistic and measurable. Adopting the management and assessment methods of project owners, formulating a series of standard construction processes and task indicators, strengthening the management and monitoring of the construction process, establishing the effective inspection mechanism and specific evaluation indicators with the teaching units as the basic units for construction. Through the necessary quality review methods, the resource construction will achieve the expected results.

(2) Focus on the social attributes of mobile learning resources. The development of mobile Internet technology, weibo and wechat are generally accepted, providing new forms and ways for social interaction, and providing strong technical support for socialized learning scenarios. Mobile learning is both an independent learning process and requires peers to help each other and motivate each other. The development of mobile learning resources should focus on the interaction between the teaching process and learning activities, give the learning resources rich context, socially promote learning and resource generation, and improve the resource use efficiency through platform linkage.

(3) Mine and integrate the teaching resources of enterprises. Learning resource construction is not simply integrating existing resources into electronic data. Instead, it needs to combine the development status and technical standards of the industry, explore the superior resources of enterprises in professional skills training, integrate the work tasks of enterprises, and train the cognitive ability of students to work. Organize professional teachers to go deep into the enterprise, touch the industry's new technologies and new standards, absorb the company's project resources, advanced technology and equipment, and integrate into production process management, business processes, job responsibilities and corporate cases. 
(4) Promote the sharing and classification of resources. The use of mobile learning resources is timeliness. Inefficient time to expand resource utilization, thereby promoting resource sharing, is the most efficient way to use resources. The various universities do not exist in isolation, and they are connected to each other and need high-quality learning resources to share. With the continuous development of technology, the network plays an increasingly important role in life. Integrating mobile learning resources with the network is more conducive to the sharing and categorization of learning resources. Especially the unlimited network has the advantage that other networks can't match.

(5) Focus on guiding the learning concept of learners. Mobile learning is based on the high self-discipline of learners. To improve the effectiveness and quality of mobile learning, we must first improve the learners' self-learning ability. Since many smart mobile devices have game entertainment or web chat functions, if learners do not have strong self-discipline, they are easily caught in games and chats. The construction of mobile learning resources requires the use of new technologies in the mobile Internet community, through the group effect to achieve the common promotion of learners, to develop plans for learners, and to develop good habits of learners.

\section{Acknowledgement}

This work is supported by Innovative training program for college students in 2017: Exploration and practice of "Chinese classics reading" into universities; Teaching reform project of Bohai university in 2015 (BDJG-15-YB-B-012); Postgraduate teaching reform project of Bohai university in 2016: Action research on "ability to advanced" under the primary school education professional master talent training mode reform; Research subject on teaching reform and on educational quality evaluation in Liaoning education evaluation association: Exploration and practice of "Chinese classics reading" into universities; "Professional degree graduate student case library" project of Bohai university in 2017: Primary school Chinese teaching design case library; Project of economic and social development in Liaoning in 2018: Research on the cultivation of core quality of normal education in the context of structural reform of supply side.

\section{References}

[1] Y. Y. Xu, "Research on Construction Scheme of Mobile Learning Resources," Software Guide, vol. 17, no. 3, pp. 224-226, 2018.

[2] C. Y. Dong, "Research on the construction of mobile learning resources in Shandong open university," Journal of Shandong Radio and TV University, vol. 21, no. 2, pp. 14-16, 2015.

[3] T. Zeng, "Construction of Mobile Learning Resource Model From Supply Side Perspective," Journal of Guangdong Polytechnic Normal University, vol. 38, no. 3, pp. 90-95, 2017.

[4] L. Le, "Research on the Construction and Application of Mobile Learning Resources," Journal of Nanjing Radio \& TV University, vol. 25, no. 4, pp. 81-83, 2017.

[5] Q. J. Tang, Y. Zhang, "Construction of network resource library based on mobile learning," Teaching \& Administration, vol. 33, no. 33, pp. 45-47, 2016.

[6] W. Liu, C. Y. Gao, M. Cui, "Construction and application of micro learning resources in mobile environment," Education Modernization, vol. 5, no. 2, pp. 65-66, 2018.

[7] X. Z. Jiang, "Research on mobile learning resource construction mode," Computer Knowledge and Technology, vol. 13, no. 8, pp. 8-10, 2017. 